\title{
LEARNING ANALYTICS TO QUANTIZE AND IMPROVE THE SKILLS DEVELOPMENT AND ATTAINMENT IN LARGE CLASSES
}

\author{
Ishwari Aghav', Jagannath Aghav ${ }^{2}$ \\ ${ }^{1}$ Cofounder, Saple Software, Pune 411021 \\ ${ }^{2}$ Professor, Computer and IT Department, College of Engineering Pune 411005
}

\begin{abstract}
The intervention of technology in the teaching and learning processes is bringing change. There is requirement of methods and techniques to analyze the generated data in these processes. Traditional way of delivery and assessment is becoming more focused by the application of technology. In this paper, we propose and illustrate an algorithmic methodology that shall allow the stakeholders in education to focus more on skills attainment effectively.

In large size class, there is huge data generated by registration system, administration system, and the learning management system together. We propose the methodology that mainly maps and quantizes the learning outcomes, and that relates to the successful and weaker range of attainments of stakeholders. This algorithmic methodology reads the data viz. course details, outcomes, and assessment scores of a large class and analyzes the skills attainment with respect to the planned each course outcome. The detailed report is generated with the average of attainment of the class strength, highest attainment, and lowest attainment in each of the course outcomes for each student.
\end{abstract}

Key Words: Learning Analytics, Software tool, System Architecture, Course Outcomes, and Skills Attainment

\section{INTRODUCTION}

Accreditation agencies in the world have outlined the required attributes of engineering graduates. The attributes are eventually mapped to the contents of curriculum that helps in the attainment and in the development skills of graduates.

Identifying and addressing good and weak attainment groups especially in large size student classes is a challenge to the Instructors. With the help of emerging educational data mining technologies and learning analytics, it is becoming feasible for focusing effectively more on learning outcomes. Analytics of data in course management will help in redesigning the course outcomes. It will produce quantized evidence for new assessment tools and implementations.

The delivery of contents is planned by Instructors in various forms. There are challenging decisions on curriculum, instruction, assessment strategies, monitoring the student performance, etc. The decision making is challenging especially when the size of class is large. Following parameters if are considered for analyzing then the challenges become even more formidable":

(a) Monitoring performance of each stakeholder,

(b) Addressing and identifying the groups that needs attention,

(c) Averaging the performance over various electives in different semesters, etc.

(d) Predicting optimal performance,

(e) Planning and redesigning effective course instructions,

(f) Designing, testing, and evaluating the course contents and relevant resources, and (g) Identifying the appropriate assessment tools and techniques.

This motivates the design of an algorithmic solution that shall facilitate the collecting, presenting, and analyzing the academic, learning, assessment, data to the meet various objectives.

\section{LITERATURE SURVEY:}

Techniques used in analyzing various engineering domains exist widely in literature. The importance of analytics is grown recently after proliferation of management information systems in everyday life. There are various categories of analytics based on domains, e.g. health analytics in health care, learning analytics in universities, business analytics in communication, insurance, and banking systems.

Learning Analytics [1, 2] is defined as "the measurement, collection, analysis and reporting of data about learners and their contexts, for purposes of understanding and optimizing learning and the environments in which it occurs."

In order to address the applications of technology in education, this context requires use of learning analytics. The usage shall help in decision making at Institute or administrative level, faculty level, and student level. Some of the useful gains (not all covered) of applying learning analytics are: increased productivity, effective resource allocations, transformation pedagogical approaches, provides interventions to risk learners, and help to students in gaining the insight on own learning. 
The online courses are reshaping with advent of technology. Traditional courses are getting transformed with addition of growth of tools and frameworks. In order of make learning effective especially in large classes, it essential to focus on parameters that shall help in planning lessons, resources, assessments, and delivery of the course in the class.

There are efforts $[3,4,6-18]$ in various directions to capture the data and apply effectively in order to improve learning. An e-learning tool [3] based on object oriented approach wherein objects are text, audio, and graphics. Upon request from student the tool dynamically creates customized course based on profile in the learning management system. There are other tools [19, 28-30] in the learning and academic analytics that aid in management of courses.

There are various approaches and methods on delivering contents [4-6]. The delivery methods [4] are transmitted to remote learning management system, which provides the contents, based on request from users. The focus is more on delivering automatically transmitting the contents to remote learning management system, and maintaining/ updating automatically the course catalog. The Academic Analysis Tool [7] is the software that analyzes student behavior which actually gives the feedback on how students use and learn in different courses.

There are applications and methods [20-27] of academic analytics, which are applied for future predictions, and also some other cases [32-36] of applying analytics in literature are available.

\section{SYSTEM ARCHITECTURE BASED ON 'LIFE CYCLE OF SUCCSSIVE SKILLS}

\section{ATTAINMENT'}

Learning in the classroom has life cycle that aims at attainment of skills. The components of cycle are: mainly the learner's interaction with instructor, content lessons, assessment tools, and the skills attainment. This is iterative cycle of improvement with duration of semesters and years.

The target course outcomes that are derived and planned from the program outcomes are set based on graduate attributes. On the basis of target outcomes, the content lessons are delivered for learning. Schematic outline showing the life cycle on successive skills attainment is depicted in FIGURE 1. The content lessons include the resource material, books, videos, etc. The cycle is iterative and it improves on growth in learning, helps in taking decisions on delivery, planning, and understanding the delivery contents.

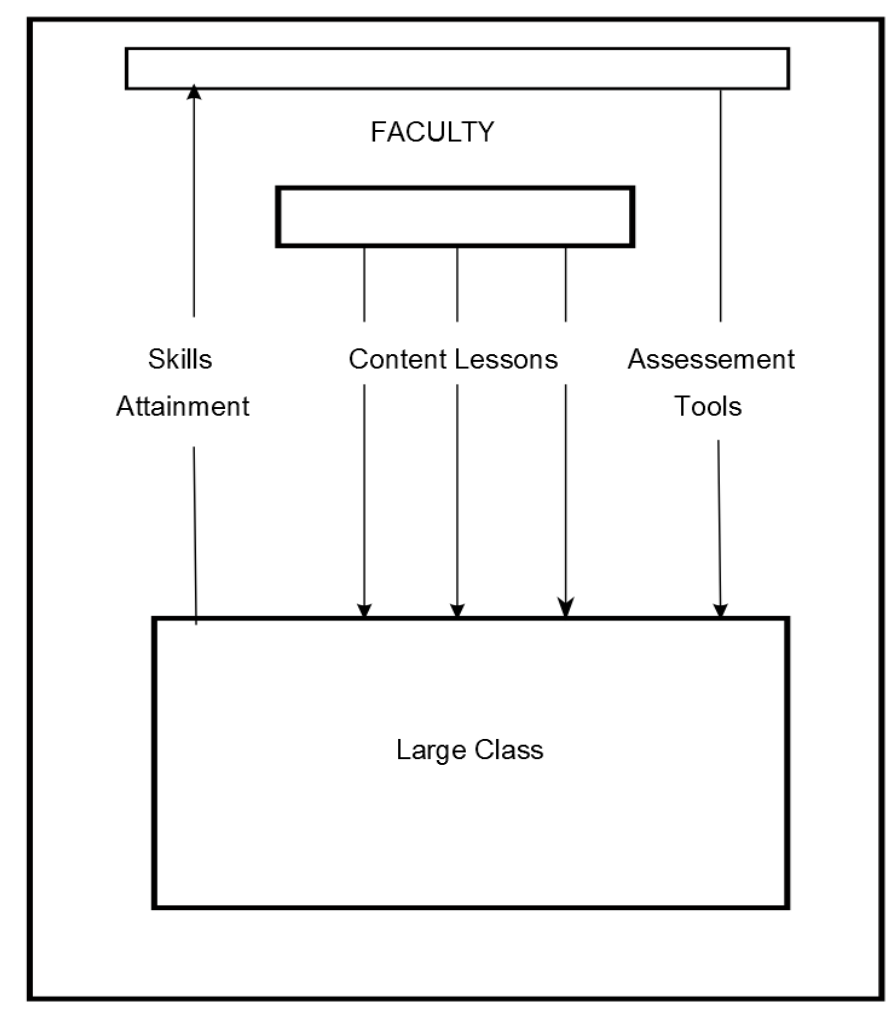

FIGURE 1: Life Cycle of Successive Skills Attainment

We have implemented the system architecture that will allow focusing on skills improvement and the attainment by using learning analytics. The methodology quantizes and maps the parameters of interest especially assessment and delivery of course contents. There is flexibility of defining and planning the different assessment sequences and weightages. The models built on these defined course assessment tools provide results on the attainment of each planned outcome.

FIGURE 2 depicts the system architecture with the layout of components and its implementation. Following are the analytical modules or components used in the system architecture:

- Assessment Design Module

- Course Outcomes Module

- Report Generation Module

- Learning Analytics Module

There two main interactive modules: one for designing course outcomes and another for designing various types of assessments. The program outcomes are mapped to course outcomes requires to be entered, as it forms the basis of performance evaluation. 


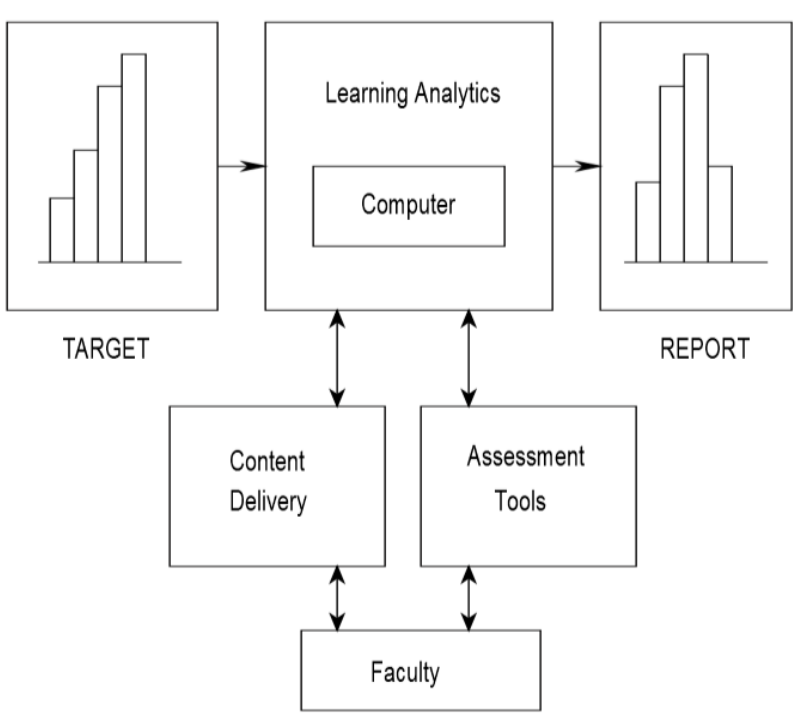

FIGURE 2: System Architecture of Implementation

The course outcomes while being entered are verified with Bloom's Taxonomy, and this will be providing the classification of each design outcome. This will help in balancing the outcomes in learning of course. The intelligent course design module shall advise the classification and also will give short-comings as feedback to the design process.

The process of entering data, classifying outcomes statements is completely independent of course contents or the subject matter. The process implementation is automated with an algorithmic solution. Automated weighted assessment in the design module is implemented with an algorithmic methodology. It allows defining the weightage of each assessment in the final computation of performance. This is useful when there are multiple assessment tools applied for continuous evaluation.

The learning analytics module and the report generation module are designed with an algorithmic methodology that provides:

(a) Average attainment of each course outcome,

(b) The list of highest attainment group,

(c) The list of lagging or weak attainment group,

(d) The complete attainment report in excel sheet and portable document format, and

(e) The record of average attainment in each case of program outcome based on multiple mapped courses.

In the next section we shall illustrate the details of the methodology by running input on sample course.

\section{ILLUSTRATIVE EXAMPLE}

In this section we shall demonstrate the implementation of the methodology on sample input course. The system architecture and methodology is tested over 50 courses in real life with each course containing 3 examinations and its corresponding laboratories.

FIGURE 3 shows the percentage of average attainment of each course outcome for the Course Title: Theoretical Computer Science, Course Code: CT-202, Semester IV, with 82 students.

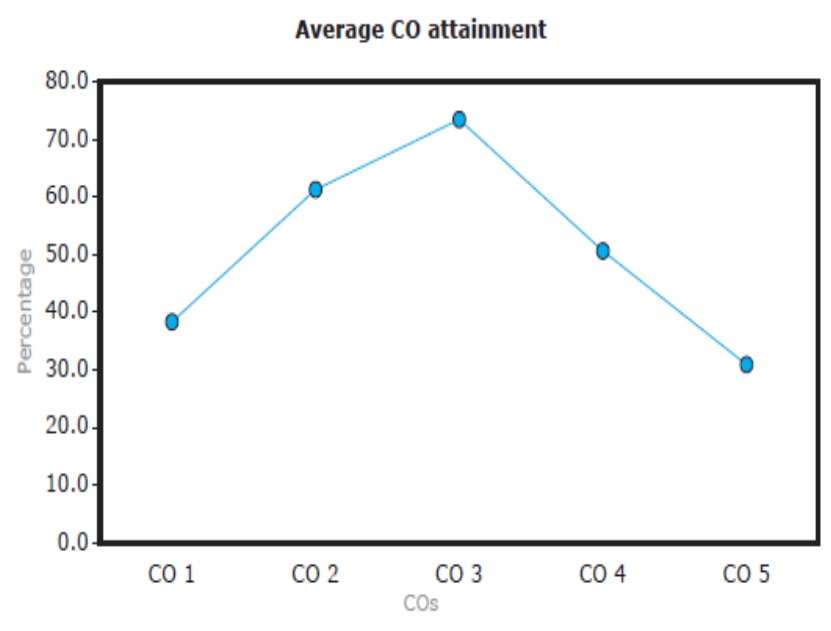

FIGURE 3: Percentage of average attainment of each course outcome

It is clear from the percentage of average course outcomes attainment that course outcome $\mathrm{CO} 3$ is highest; while as course outcome $\mathrm{CO} 1$ and $\mathrm{CO} 5$ attainment needs attention, and accordingly the planning for the lessons to strengthen further.

TABLE 1 shows the course outcomes attainment with number of students achieving with $75 \%$ and above and the lagging behind on $35 \%$ and below. For example the course outcome CO 2 has 8 students lagging behind by score 9.88 $\%$ or below.

\begin{tabular}{|ccc}
\hline & $\begin{array}{c}\text { Number of students } \\
\text { achieving } \\
\text { 75\% or more }\end{array}$ & $\begin{array}{c}\text { Number of students } \\
\text { achieving } \\
\text { less than 35\% }\end{array}$ \\
\hline $\mathrm{CO} 1$ & $5(6.17 \%)$ & $34(41.98 \%)$ \\
\hline $\mathrm{CO} 2$ & $22(27.16 \%)$ & $8(9.88 \%)$ \\
\hline $\mathrm{CO} 3$ & $46(56.79 \%)$ & $5(6.17 \%)$ \\
\hline $\mathrm{CO} 4$ & $7(8.64 \%)$ & $10(12.35 \%)$ \\
\hline $\mathrm{CO} 5$ & $7(8.64 \%)$ & $53(65.43 \%)$ \\
\hline
\end{tabular}

TABLE 1: Course outcomes attainment with number of students

The course outcomes CO 1 and CO 5 have 5 and 7 students respectively with attainment of $75 \%$ or above. The number of students with lagging behind in the attainment of course outcomes CO 1 and CO 5 is more. This cyclic feedback shall help in planning the lessons, in designing outcomes, and in adoption of the next assessment tools and methods.

\section{DISCUSSION}

The algorithmic implementation demonstrates an illustration of iterative cycle of improving the skills attainment. The presented methodology quantifies the attainment and provides the detailed reports. By analyzing the generated reports it is feasible to address the weaker groups with respect to the outcomes.

In future there is also need to quantify and map the iterations for benchmarking excellence in courses. The feedback of the iterations shall bring the improvements in each step of the learning process. 


\section{REFERENCES}

[1] Learning Analytics, on Wikipedia URL: http:// en.wikipedia.org/ wiki/ Learning_analytics.

[2] Tanya Elias, "Learning Analytics: The Definitions, the Processes, and the Potential", January, 2011.

[3] Mark Rukavina, Chris Dragon, Mike Ray, Carman, etal., "E-Learning Tool for Dynamically Rendering Course Content," Patent US 2002/ 0188583 A1, Dec 12, 2002.

[4] Robin U Sperle and Marcus Philipp, "Delivery Methods for Remote Learning System Courses," Patent US 2007/ 0111180 A1, May 17, 2007.

[5] Sarah Buchanan and Joseph J Laviola, " CSTutor: A Sketch-Based tool for Visualizing Data Structures," ACM Transactions on Computing Education, Volume 14 Issue 1, pp. 3:1- 3:27, March 2014.

[6] Steven Lonn, Andrew E., Krumm, R. Joseph, Stephanie D., "Bridging the Gap from Knowledge to Action: Putting Analytics in the Hands of Academic Advisors", LAK'12, Vancouver, BC, Canada, April 29-May 2, 2012.

[7] Sabine Graf, Arnold Ferri, "AAT - A Tool for Accessing and Analyzing Students Behavior Data in Learning Systems", LAK'11, Banff, AB, Canada, February 27-March 1, 2011.

[8] Gonzalo M., Xavier O., Katherine C., "Techniques for Data-Driven Curriculum Analysis", LAK '14, Indianapolis, IN, USA, March 24 - 282014.

[9] Angela van Barneveld, Kimberly E. Arnold, and John P. Campbell, "Analytics in Higher Education: Establishing a Common Language", January 2012.

[10] Stuart Palmer, "Modelling Engineering Student Academic Performance Using Academic Analytics", International Journal of Engineering Education Vol. 29, No. 1, pp. 132-138, 2013.

[11] Taeho Yu, II-Hyun Jo, "Educational Technology Approach toward Learning Analytics: Relationship between Student Online Behavior and Learning Performance in Higher Education", LAK '14, Indianapolis, IN, USA, Mar 24-28 2014.

[12] Dehler, C. (2004). Best Practices for Effective Online Teaching. In R. Ferdig et al. (Eds.), Proceedings of Society for Information Technology \& Teacher Education International Conference pp. 407-412, 2004.

[13] Eleni Koulocheri, Alexandros S., Michalis X., "Applying Learning Analytics in an Open Personal Learning Environment", 16th PanHellenic Conference on Informatics, 2012.

[14] Kimberly E. Arnold, Matthew D. Pistilli, "Course Signals at Purdue: Using Learning Analytics to Increase Student Success", LAK'12, Vancouver, BC, Canada, April 29 - May 2, 2012.

[15] Philip J., Daniel T., MJ Bishop, "Educational Data Sciences - Framing Emergent Practices for Analytics of Learning, Organizations, and Systems", LAK '14, Indianapolis, IN, USA, March 24 - 282014.

[16] Eitel J.M. Lauria, Joshua D. Baron, Mallika Devireddy, "Mining academic data to improve college student retention: An open source perspective", LAK'12, Vancouver, BC, Canada, 29 April - 2 May 2012.
[17] Eitel J.M. Lauria, Erik W. Moody et al., "Open Academic Analytics Initiative: Initial Research Findings", LAK '13, Leuven, Belgium, April 08 - 12, 2013

[18] Stephen Aguilar, Steve Lonn, Stephanie D., "Perceptions and Use of an Early Warning System During a Higher Education Transition Program", LAK '14, , Indianapolis, IN, USA, March 24 -28, 2014.

[19] Campbell, J. P., DeBlois, P. B., Oblinger, D. G., "Academic analytics: A new tool for a new era", Educause Review, 2007.

[20] Educause, "Academic Analytics in the future of higher education", ECAR Research Study 8, 2005.

[21] John P. Campbell and Diana G. Oblinger, "Academic Analytics", Educause, October 2007.

[22] Jacqueline Bichsel, "Analytics in Higher Education", ECAR Research Study 8, 2012.

[23] Judith A. Pirani, Bob Albrecht, "University of Phoenix: Driving Decisions through Academic Analytics" ECAR Case Study 9, 2005.

[24] Philip J. Goldstein, Richard N. Katz, "Academic Analytics: The Use of Management Information and Technology in Higher Education”, ECAR Research Study, Volume 8, 2005.

[25] M.A. Chatti, A.L. Dyckhoff, U. Schroeder, and H. Thus, "A Reference Model for Learning Analytics", International Journal of Technology Enhanced Learning.

[26] Malcolm Brown, "Learning Analytics: The Coming Third Wave", April 2011.

[27] Beth Dietz-Uhler and Janet E. Hurn, "Using Learning Analytics to Predict (and Improve) Student Success: A Faculty Perspective", Journal of Interactive Online Learning, Volume 12, Number 1, spring 2013.

[28] Ravi Shankar, Jonathan Dickson and Carlo Mazoleny, "A Tool for ABET Accreditation", 120th ASEE Annual Conference and Exposition, Atlanta, GA, June 2013.

[29] Eugene Essa, Andrew Dittrich, Sergiu Dascalu, Frederick C. Harris, Jr., "ACAT: A Web-based Software Tool to Facilitate Course Assessment for ABET Accreditation", Seventh International Conference on Information Technology, IEEE, 2010.

[30] Eugene O. Essa, "ACAT: ABET Course Assessment Tool", Thesis report, University of Nevada, May, 2010.

[31] Dr. Tanya Gorman, "Assessing Student Learning Outcomes", COC Summer Institute, 2008.

[32] Rebecca Cartwright, Ken Weiner, and Samantha Streamer-Veneruso, "Student Learning Outcomes Assessment Handbook", revised August, 2009.

[33] Norris, D., Baer, L., Leonard, J., Pugliese, L., Lefrere, P., "Action analytics", Educause Review, 2008.

[34] Paul Baepler, Cyntia James Murdoch, "Academic Analytics and Data Mining in Higher Education", International Journal for the Scholarship of Teaching and Learning (IJSOTL), Volume 4, No. 2, Article 17, 2010.

[35] Bandura, A., "Self-efficacy: The exercise of control", New York: Freeman \& Co., 1997.

[36] Cross K. P., "Thirty years passed: Trends in general education.", in B. L. Johnson (Ed.), General education in two-year colleges, San Francisco, 1982, pp. 11-20. 


\section{BIOGRAPHIES}

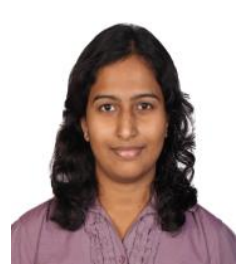

Ms Ishwari Aghav has obtained Bachelor of Information Technology from PICT Pune (affiliated to University of Pune) and is the cofounder of start-up Saple Software Pune India.

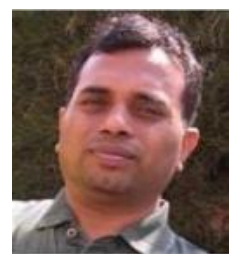

Jagannath Aghav has obtained PhD in Computer Science from Tata Institute of Fundamental Research (University of Mumbai) India. $\mathrm{He}$ is working as Professor in Computer and IT Department of College of Engineering Pune India. 